\title{
The Development of School Physical Education in the Cultivation of Lifelong Sports Consciousness
}

\author{
Kaijun Ji, Kaibin Ji, Xueshan Li \\ Competitive Sports, Aviation University of Air Force, China \\ jingyuanshishi@sina.com
}

\begin{abstract}
School physical education plays an essential role in system of lifelong sports, as well as a link connecting social education and family education. It also acts as an important part in the implementation of lifelong sports. Therefore, the lifelong sports development, aiming at students of all stages under the school education, is very scientific and rational. It is also meaningful to improve the physical quality of the teenagers, and strengthen China's national overall physical quality.

Index Terms - lifelong sports, school physical education, interests, habit, abilities
\end{abstract}

\section{Introduction}

With the development of society and the continuous improvement of living standard, people pay more and more attention to physical health. Advocating consciousness of lifelong sports has been gradually recognized. The so-called lifelong sports indicate a person take lifelong exercise, and accepts sports education. ${ }^{[1]}$ The whole process of the lifelong sports education is made up of family education, school education and social sports. ${ }^{[2]}$

School physical education plays an essential role in system of lifelong sports, as well as a link connecting social education and family education. It also acts as an important part in the implementation of lifelong sports. School sports are an important stage to develop the lifelong sports consciousness. Because the amount of time, which a person accepts systematic physical theoretical education and the physical technical practice at school, is the longest. There are a great number of professional physical teachers to offer the students guidance, as well as a lot of physical facilities and stadiums offered for students to take exercise. In the stage of school physical education, whether the development of the lifelong sports consciousness is good or not will have direct effect on their lifelong value of physical education and the ability of independent practice. In the meanwhile, the physical conditions of teenagers are in the golden age of growth and development, which should be made good use of to build correct the lifelong physical education consciousness, and stimulate their interests towards physical sports, develop physical habits as well as improve physical abilities, providing the fair guarantee for teenagers' jobs and life after they step into society.

Therefore, the lifelong sports development, aiming at students of all stages under the school education, is very scientific and rational. It is also meaningful to improve the physical quality of the teenagers, and strengthen China's national overall physical quality.

\section{The Concept of Lifelong Physical Education}

Lifelong physical education has been affected by the opinions of international lifelong education, and put forward with the development of physical education. It was Wang Zeshan that first put forward the view of lifelong physical education in China, considering lifelong physical education as "a person take lifelong exercise, and accepts sports education". ${ }^{[3]}$

Lifelong physical education, refers the sum of a person take lifelong exercise, and accepts sports education. Lifelong physical education consists two aspects, one refers a person carries out continued physical exercise during his lifetime in order to achieve the purpose of body building and promotion the development of physical and mental health, the other one indicates that under the guidance of lifelong physical education views. With the target and means of systematic, integrated and scientific physical education, it offers the participation of physical exercise in human life's different stages and fields, as well as the practice process of ideological education opportunities. The main ideas of lifelong physical education is letting one accept continuous physical education during his lifelong time and take lifelong physical exercise, making pre-school education, school education, family education, social education and other links connected closely with physical education in order to guarantee the unity, integrity and continuity of the physical education, and realizing its integration. ${ }^{[4]}$

\section{The Stage Division of the Development of Lifelong Physical Education}

Lifelong physical education, namely a person should accept physical education and take physical exercise during lifetime. Physical needs and the purpose and methods of taking exercise differ from person to person, during different stages of lifetime. Physical exercise is not permanent or complete. With the physical change and different ages, update the exercise contents and methods and develop lifelong consciousness in a gradual and distinguished way.

According to the growth regular pattern of human beings, a person's life can be divided into five stages, childhood, juvenile period, adolescence, middle-age period and senescence. According to the social process of men's growth law and experience, lifelong physical education can be divided into family education, school education and social education. (Figure1) In the picture the school education is a very essential developing stage of lifelong physical education, a link connecting family education and social education. 
The school education, working as an essential performing stage of lifelong physical education, lays a solid foundation for the development of lifelong physical education consciousness. The school education mainly consist of three stages, they are primary education, secondary education and higher education. Thus, it has very essential theoretical meaning and practice value for fulfilling the lifelong physical education to analyse the teaching condition and the students' characteristics of different stages, and advise developing the lifelong physical education consciousness for the teenagers. ${ }^{[5]}$

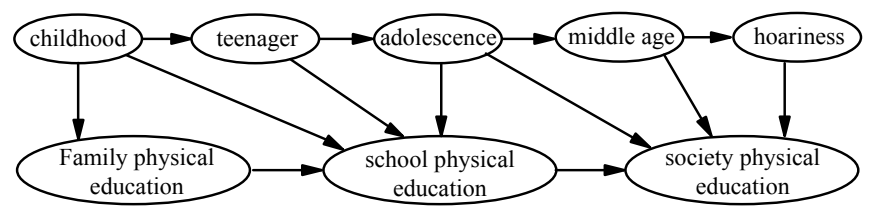

Fig.1.The inter-relationship of the social process between the growth of people and experience

\section{The Function of School Education to the Development of Lifelong Physical Education Consciousness}

The school education is an important part of fulfilling lifelong physical education, playing an essential role. The age of the students who receive school education is between 8-23, which is the most vigorous period for the mental and physical development in this stage, from child to adult, which is spent during school. Therefore, whether the effect of school education is good or bad will directly affect one's lifelong physical education consciousness as well as physical health.

First of all, the theoretical knowledge of physical education is a reasonable guidance for performing physical exercise. At school, There exist a great number of professional teachers give lessons to the students on systematic theoretical knowledge of physical education. Modern school physical education sets courses on physical education theory as follows, Physical Education and Health, Exercise Physiology, Exercise Anatomy, Health Fitness Education and other theoretical books, which are available for students for free. Only with rich physical education knowledge, will we carry out reasonable and scientific physical exercise, as well as avoid the physical injury caused by blind exercise.

Secondly, school can develop the students' lifelong physical education consciousness through PE class, which accompany all the students from the moment they step in the school life, throughout all their school lifes. During the period of school, the PE class lasts from the first grade in primary school to grade three in university, whose total amount of time is up to above 1500 hours. During the different stages of school physical education, PE teachers will set up teaching contents and methods corresponded with the students' physical and mental development characteristics. In the implement of teaching, PE teachers should constantly update their own teaching concept, make their students from active learning to passive learning, establish the dominant role of the students, and create a harmonious as well as active PE class, bringing an active influence on both physical and mental aspect of the students.

Thirdly, school has a relatively strong cultural atmosphere in the school lifes, acting as an active and promoting role in the development of lifelong physical education value. School's setting up optional classes makes it convenient for the students to choose the subjects they are interested in to take exercise, according to their hobbies, which also respects the individual difference of the students. School organizes various competitions and performances regularly, build a platform to express themselves, and increase the students' sense of confidence and success, making them have more motivation to take exercise.

Last, school has enough sports facilities and stadiums, and the students can make full use of their spare time to take exercise at any time, which not only relieves their learning pressure, achieves the combination of learning and sports, but also enriches their spare time, develop the physical habits, improve sports abilities, and creates advantages for the lifelong physical education to achieve the effective implement in the school education. Therefore, the stage of school education is the most direct and effective stage to develop the lifelong physical education.

\section{A. The Meaning for the Higher Education Stage to Develop Lifelong Physical Education Consciousness}

The college graduates will step into society, which means they will leave the school education in the near future. Higher education acts as the final systematic learning stage before the individual steps into society, which is the sprint phase stage to step into social physical education, playing an important role in the creation of lifelong physical education views. The physical education in the primary education stage fixes attention on the interests in development, the physical education in the secondary education stage fixes attention on the development of students'physical habits, while the physical education in the higher education stage has changed into the final stage of social physical education. After the students went through the primary, secondary physical education, the college students should be better on the basis of the physical health condition, physical education interest, and physical education, and the acceptable ability is the fastest. So the college students should master deeper aspect of the theoretical knowledge of the physical education and apply the improvement their individual physical abilities as main teaching targets, providing more powerful guarantee to possess the independent sports abilities after the students step into society.

The physical education consciousness keeps a relative long distance from the teaching target in the college physical education on the whole through the analysis and arrangement of the document. Nowadays, the condition of most college students is that most students appreciate physical education as the identity of audience, while the number of the students who can participate in the physical education is very small. The purpose of the their attending PE class is to complete a course, and they haven't recognize the importance of the physical exercise, who can't insist in automatic exercise. 


\section{B. Physical Education in Higher Physical Education Improve the Students' Sports Abilities}

Higher physical education is the last aspect of school physical education, the college students' physical learning ability has improved, as they grow older, levels of knowledge improve. Their main resource of participating in the physical education is the exercise foundation built in primary or middle school. The college physical education should be based on the present, with eyes on the future. The college students experience the primary physical education to stimulate interests, the habit's development of the physical education in the secondary stage. They have stepped into the college, and have the basic fundamental physical habits, aiming at the present situation of the college students' implement of physical activities, and advising the college classes should a physical education mode corresponded with their characteristics. If we want to develop the physical education consciousness on the basis, we should improve their physical abilities, encourage them to have a deeper understanding of the physical theoretical knowledge, form a habit of healthy living manners, have a more experienced grasp of the physical techniques, laying a solid foundation for the physical exercise after they leave school and step into society. Therefore, in order to build the class of physical education, we should improve our teaching methods of PE class, pay more attention to the teaching of a physical education theoretical knowledge, offer enough physical education facilities, and create a better physical environment for the students to enhance their physical education consciousness, improve their physical abilities, and form the habit of lifelong physical exercise.

\section{The Approach of Developing the Students' Lifelong Physical Education Consciousness in the Stage of Higher Education \\ a) Attach more importance to the teaching of deeper physical education theoretical knowledge}

The so-called "teach them to get fish" is better than " teach them to fish". That is to say, making the students take exercise is worse than teaching them scientific and reasonable methods of taking exercise in order to stimulate their conscious movement. The sports health knowledge is the basis of all physical sports, which plays an important part in lifelong physical education. Therefore, on the basis of advising the universities to teach hierarchically and division of different grades, let the students get to know basic physical medical knowledge, including the characteristics of human physical structure, physiological function and psychological characteristics, as well as the contents of individual sports health care, safety education and the preventin of accidents. Enrich the individual foundation of physical theoretical knowledge, get to know their own physical condition, how to take exercise reasonably and scientifically and how to prevent the occurrence of physical sport injury.The physical fundamental knowledge sets a definite direction for the college students to know how to take scientific and reasonable exercise.
So the college education must strengthen the teaching of physical theoretical knowledge. Our attitude towards the physical theoretical class should not be dispensable. We should strengthen the teaching of physical theoretical class, get to know the development of your physical condition, arrange for the scientific exercise, and avoid the injury caused by blind physical exercise. Making the students truly realize the meaning of physical exercise and evaluating the value of college students' sports lay a solid foundation for lifelong physical education.

\section{b) The transformation of teaching mode of higher education}

In the course of teaching, we should arrange some teaching contents corresponded with the characteristics of the students, and change the competitive items into the entertaining physical activities. Because the thinking of the college students is mature, and have a basic physical education foundation. Therefore, the former teaching mode, that the teachers teach in the front of the classroom, while the students learn in the corner of the classroom, has conformed to the modern efficient classroom. If we want to build a more efficient class, we should change the former single and dull teaching method into a method which is changed from a communicative one. For example PE class. Nowadays, teenager have get the hang of basketball, so there is no need to teach them hand by hand, but to encourage the students to do some research on a concrete technical movement. For the target of the contemporary school physical education is to build the thought of "Health First", develop the students" lifelong physical education consciousness, rather than the professional technical level that the students want to achieve. So, in class, we should adopt a teaching method which is the combination of theoretical knowledge and practice, as well as competition and interest. We should create a relaxed and natural atmosphere, and let the teachers and students interact freely, with everybody involved. For instance, teachers and students can play basketball together. In this way, they can develop a close relationship, and correct the movements under the guidance of the PE teachers. This teaching method can motivate the learning subjective initiative of students, and change the teachers' active teaching into the students' active learning.

c) Create a strong cultural atmosphere of the physical education in the university campus

The development of physical education consciousness of the college students is closely connected with the strong cultural atmosphere of the physical education. The cultural activities of physical education in the university campus consist of morning exercise, recess activities, after-class activities, PE class as well as different kinds of competition, and physical facilities as well as physical stadiums, and other substantial environment, which is an important factor that attracts the students to take physical exercise. In order to develop the physical exercise interest for the students, grasp the basic skills, we should improve their physical abilities to offer advantageous foundation of the environment. 
In order to create a strong school physical education cultural atmosphere, first we should take various kinds of physical competition actively, which can not only enrich students' spare cultural life, but also stimulate students' learning interests, increase students' physical abilities, and form a good habit of insisting on physical exercise. Such as, develop sports and art performances, which are as follows, aerobics, Latin dancing, sports dancing, figure dance. Ball games are, basketball, football, volleyball, table tennis, and so on. We can encourage more students to take part in the physical activities that they like best to show their own physical elegant demeanour, to improve their physical taste, and find the beauty of sports through holding various physical activities.

Secondly, creating a campus physical education cultural atmosphere makes the students take exercise willingly, consciously and independently. Therefore, we must get the students to firmly grasp relatively systematic physical and medical health care knowledge as well as physical basic skills in technology. School should invite experts to give lectures on physical knowledge regularly, which is also the most important channel for the students to acquire physical knowledge. In addition, we can also organize the students to watch sports events so as to know the current affairs' trend in the sports fields, and widen the students' horizon. It is not only beneficial to edify sentiment of the students, but also increase their interest towards physical activities, which is also an important means for the students to develop their passion physical activities as well as appreciate the beauty of sports and the communication between students and teachers.

Lastly, school should pay more attention to strengthen the construction of physical facilities and sports stadiums, which are the substantial guarantee to set up school physical and cultural atmosphere and develop physical activities, without which the construction of school physical culture is not available. School should spare no effort to create an excellent physical condition for the college students, update the sports facilities regularly, strengthen the usage and management of the sports stadiums, and make use of the present sports facilities to the fullest, in order to create an excellent exercise conditions and lay a solid foundation for the improvement of the students' physical abilities.

\section{Conclusion}

Lifelong physical education refers to a person who carries out physical exercise and accepts physical education for all his life. During the different stages of human's life, the physical needs and exercise as well as methods differ from person to person. Physical exercise is not permanent. With the change of age and physical condition, we should update the contents and methods of physical exercise, and develop the physical education consciousness in a gradual and distinguished way. Primary education stage stimulates the interest of students. The main form of stimulating physical exercise is playing games in the stage of childhood, through various and interesting PE class to stimulate the interest of primary students to carry out physical activities. Secondary education is to develop the good habits for the students to take exercise. The characteristics of China education determines the contradictoriness with physical exercise. Therefore, strengthening human's physical health conditions and developing good habits of taking exercise have become the main content for the physical education in this stage. Higher education is to improve the physical abilities of students. With the development of age and levels of consciousness, the requirements and recognition of the college students towards physical activities have gradually increased. The method for the school education to develop lifelong physical consciousness suggested is as follows, stimulation of the interest towards physical activities - develop the habit of physical activities - improvement of physical abilities, which should be carried out according to the teaching target and age in a gradual and connected way.

\section{References}

[1] Wang Zeshan. The Research Towards Lifelong Physical Education. Journal of Beijing Sports University,1987,(1): 35-39.

[2] Shao Weide. The Lifelong Physical Habitual Inner Theoretical Structure. Journal of Sports, 2003, (1): 66-69.

[3] Chen Zhiyue. The Inspiration of Foreign School Physical Education to China's Physical Education Development in next 10 years. Journal of Capital Institute of Physical Education, 2006, (13): 49-51.

[4] Xie Yifei, Zhang yuedong. The Periscopic and Summary of Lifelong Physical Education Research. Shandong Sports Science and Technology, 1994, (4):9.

[5] Cui shulin.The Division and Analysis of Lifelong Physical Education. Journal of Sports, 2008, (5): 57. 